\title{
Emerging trends: Artificial Intelligence, China and my new job at Baidu
}

\author{
K E N N E T H W A R D C H U R C H \\ Baidu, Sunnyvale, CA, 94089, USA \\ e-mail: kennethchurch@baidu.com
}

(Received 24 April 2018; accepted 25 April 2018)

\begin{abstract}
It is amazing that I have written for more than a year on Emerging Trends without mentioning China's investments in Artificial Intelligence (AI). Now that I have moved to Baidu, I would like to take this opportunity to share some of my personal observations with what's happening in China over the past 25 years. The top universities in China have always been very good, but they are better today than they were 25 years ago, and they are on a trajectory to become the biggest and the best in the world. China is investing big time in what we do, both in the private sector and the public sector. Kai-Fu Lee is bullish on his investments in AI and China. There is a bold government plan for AI with specific milestones for parity with the West in 2020, major breakthroughs by 2025 and the envy of the world by 2030 .
\end{abstract}

\section{My new position at Baidu}

It is amazing that I have written for more than a year on Emerging Trends without mentioning China. My life has changed dramatically since my last column. I now work for Baidu. If you do not speak Chinese, you may not have heard of Baidu, but you will soon. Chinese speakers know that Baidu is the largest search company in China. The Chinese market is so large that it is possible for a company with relatively little brand awareness outside China to be the second largest search company in the world. ${ }^{1}$

Baidu does many things in addition to search. Some are more relevant to what we do (such as speech-to-speech translation), ${ }^{2}$ and some are less relevant to what we do (such as self-driving cars). ${ }^{3}$

\section{Education in China}

When I was president of the ACL, I performed a marketing analysis to see where the ACL membership was already strong, and where there were opportunities to grow the

${ }^{1}$ https://en.wikipedia.org/wiki/Baidu

2 https://www.theverge.com/circuitbreaker/2017/9/25/16363250/baidutranslator-gadget-announced

${ }^{3}$ https://www.wired.com/2015/12/baidus-self-driving-car-has-hit-the-road/ 
ACL membership. For each country, I looked at three variables: ACL membership, population and graduate students. Countries with more ACL members per capita were considered relatively strong, and countries with more students in areas of interest (appropriately normalized) were considered opportunities for growth. It should come as no surprise that China was identified as the top opportunity for growth.

The top universities in China have always been very good, but they are bigger and better today than they were then, and they will continue to improve. The first time I visited Tsinghua, the 'MIT' of China, things were so bad that I had to step over the ceiling, which had fallen down onto the floor. Nevertheless, I was impressed with the audience. The rest of the world was so busy with silly start-ups that no one had time to think about what they were doing. Whereas in China, since there was no possibility to make a quick buck, top students at top universities had the time to read the literature and think deep thoughts. They could dream about studying abroad, and a few had already done so.

Since then, Chinese universities went through a major expansion. Toward the end of the expansion, I had an opportunity in 2008 to give an invited talk to a number of deans in China. I suggested that my son, who was in middle school at the time, might get his $\mathrm{PhD}$ in China because that might be the place to go in his day. We come from a long line of academics. My father and his father and I received our PhDs in America because that was the place to go in our day, but my great grandfather went to Germany for his $\mathrm{PhD}$ because that was the place to go in his day. The deans could not imagine that China might be the place to go in the foreseeable future, but the next generation of students are more bullish on Chinese universities than the last generation of deans.

The narrative is that schools in America are better and more diverse than schools in China. While that may still be the case, the gap is closing. I am told that Tsinghua is now even harder to get into than MIT. The best of a billion people are really good. Tables 1 and $2^{4}$ show that top schools in China have more international

${ }^{4}$ How many students are there in top schools, especially areas that we care about? It is hard to come up with a compelling apples to apples comparison. Should we count both undergraduate and graduate students? Which areas do we care about? The list of schools in Tables 1 and 2 come from:

(1) https://www .usnews.com/education/best-global-universities/search? region $=\&$ country $=$ china\&subject $=$ computer - science\&name $=$

(2) https://www.usnews.com/best-graduate-schools/top-engineering-schools/ computer-engineering-rankings?int $=9 \mathrm{~d} 0 \mathrm{e} 08 \&$ int $=\mathrm{a} 06908$

Estimates of the other columns come from those pages, as well as:

(1) https://admission.princeton.edu/how-apply/admission-statistics

(2) https://news.harvard.edu/gazette/story/2013/03/college-admits-2029-5-8percent-of-applicants/

(3) https://collegeadmissions.uchicago.edu/apply/applicants/international

(4) https://www yale.edu/about-yale/yale-facts

(4) https://undergrad.admissions.columbia.edu/ask/faq/topic/405

(5) http://web.mit.edu/facts/enrollment.html

(6) https://diversityandaccess.stanford.edu/diversity/diversity-facts

(7) https://www.upenn.edu/about/facts 
Table 1. Top schools in the world

\begin{tabular}{lrc}
\hline \hline School & Students & \% International \\
\hline Princeton & 8,181 & 13 \\
Harvard & 20,324 & 10 \\
University of Chicago & 13,322 & 24 \\
Yale & 12,458 & 36 \\
Columbia & 25,084 & 19 \\
MIT & 11,376 & 29 \\
Stanford & 16,914 & 9 \\
University of Pennsylvania & 21,826 & 24 \\
\hline \multirow{2}{*}{ Average } & 16,186 & 21 \\
\hline \hline
\end{tabular}

Table 2. Top schools in China have lots of students, and more diversity than I had appreciated

\begin{tabular}{lcc}
\hline \hline School & Students & \% International \\
\hline Tsinghua University & 42,089 & 9 \\
Huazhong University of Science and Technology & 56,140 & 5 \\
Zhejiang University & 50,051 & 6 \\
Shanghai Jiao Tong University & 37,288 & 6 \\
Southeast University & 32,464 & 5 \\
Peking University & 42,136 & 14 \\
Harbin Institute of Technology & 29,395 & 9 \\
\hline Average & 41,366 & \multirow{2}{*}{8} \\
\hline \hline
\end{tabular}

students than I would have thought based on my admittedly limited experience. More importantly, these tables show that the top schools in China have more students than top schools elsewhere (41k students/school $\gg 16 \mathrm{k}$ students/school). This is especially true in areas of interest to this community. Top schools in China are particularly strong in engineering.

Numbers can be a bit mind-numbing. I began to appreciate the growth opportunity when I gave a talk at a summer school in Beijing in 2011. The large auditorium was completely sold out, even though the event was put together with short notice at the last minute. I came away with the impression that there were more NLP students within a few miles of that auditorium than in the rest of the world.

The experience reminded me of a keynote I gave at EACL-1993 on the revival of empiricism. It was clear that empiricism was about to take off when the talk did better with the next generation of students than the last generation (of old fogies).

The students are the future. We should invest in whatever they are doing. Back in 1993, that was empiricism. These days, there are lots of young people in China working on deep nets. 


\section{China is investing big time in what we do}

Amazing things are happening in Artificial Intelligence around the world, and especially in China. Many of these investments are having a positive impact on research in areas that we care about such as natural language processing and speech.

In a recent Commencement Address at Columbia, ${ }^{5} \mathrm{Kai}-\mathrm{Fu}$ Lee pointed out that enrollment in AI at Columbia has increased from 80 to 800 over the 34 years since he was an undergraduate at Columbia. He called out a few of the driving forces behind this increase in enrollment, some of which he is investing in: phones, banking (loans), face recognition (payments), self-driving cars and medicine. As chairman and CEO of Sinovation Ventures, a \$1B fund that invests in AI companies in China, $\mathrm{Kai}-\mathrm{Fu}$ is bullish on his investments in AI and China. In China, people like him are treated like rock stars. ${ }^{6}$

$\mathrm{Kai}-\mathrm{Fu}$ has considerable experience in areas close to ours. After graduating from Columbia in $\mathrm{AI}$, he earned a $\mathrm{PhD}$ at $\mathrm{CMU}$ in speech. Since then, he has held executive positions at Apple, Microsoft and Google.

$\mathrm{Kai}-\mathrm{Fu}$ has first-hand knowledge working for American companies in China. In a speech at the Davos World Economic Forum on the development of China, European and American venture capital and technology companies, ${ }^{7}$ he listed four reasons why American companies encounter so many difficulties in China. Two of his four reasons are (1) talent:

China's top talent, from undergraduates to professional managers, used to think that foreign companies were the best jobs. Most now see China's big companies - such as Baidu, Alibaba and Tencent - medium-sized companies - such as Meituan, Didi and Xiaomi - and startups such as VipKid and Face++ - as better options. Without the best talent, the development prospects of foreign companies in China is not optimistic.

and (2) leadership:

The heads (general managers or CEOs) of American companies in China are always foreigners who barely know anything about the country. They usually start their jobs in smaller countries, get promoted to general manager of China general and return to headquarters for their next promotion. But their main skill is sales, and they neither know nor care about product technology. They don't understand Chinese, don't speak Chinese and have no long-term commitment to China. And they are mainly responsible for the headquarters index, and their biggest wish is to protect their job. They only report good news and ignore the bad. These people are vulnerable to the fighters who head up domestic Chinese companies.

In addition to the private sector, the Chinese government is also investing big time in what we do. Technology Review, MIT's alumni magazine, ${ }^{8}$ cites a bold Chinese

\footnotetext{
${ }^{5}$ http://engineering.columbia.edu/kai-fu-lee-speech

6 'Meet the Chinese tech guru bigger than Justin Timberlake'' https://edition.cnn.com/ 2015/09/25/asia/china-innovation-kai-fu-lee/index.html

7 https://pandaily.com/kai-fu-lee-american-companies-struggle-china/

${ }^{8}$ https://www.technologyreview.com/s/609038/chinas-ai-awakening
} 
government AI plan ${ }^{9}$ with specific milestones for parity with the West in 2020, major breakthroughs by 2025 and the envy of the world by 2030 .

The Chinese government has delivered in the past on ambitious plans like this. Technology Review mentions high-speed trains as a precedent where a similarly ambitious plan produced impressive results. So too, we should expect impressive results from the Chinese investment in AI (and what we do). Technology Review quotes Andrew $\mathrm{Ng}$, who was at Baidu at the time:

When the Chinese government announces a plan like this, it has significant implications for the country and the economy... It's a very strong signal to everyone that things will happen.

\section{Is the glass half full, or half empty?}

The Technology Review article mentioned above is subtitled: 'The West shouldn't fear China's AI revolution. It should copy it.' There is considerable excitement around the world about AI, but there are also fears, especially in the West, largely involving privacy and job security, ${ }^{10}$ and even the future of humanity. ${ }^{11}$

Technology Review suggests the job security question plays differently in the West and the East.

[China's] political and business leaders are betting that AI can jump-start its economy. In recent decades, a booming manufacturing sector...have helped bring hundreds of millions of people out of poverty, creating business empires and transforming Chinese society. But manufacturing growth is slowing... Applying artificial intelligence may be the next step... While many in the West fret about AI eliminating jobs and worsening wealth and income inequality, China seems to believe it can bring about precisely the opposite outcomes.

The West and the East have much in common, but there are also many differences. There is more fear in the West and more optimism in the East. This trend holds for many things that go well beyond job security.

\section{Face recognition}

Consider face recognition technology, a technology that can be used to do many things, some good and some not so good. It is easy to be pessimistic about the downsides, but there are plenty of upsides to be optimistic about. While the West finds it creepy to live in a world with millions of cameras, ${ }^{12}$ the people that I talk to in China believe that cameras reduce crime and make people feel safer.

I am reminded of the history of answering machines. When answering machines were first introduced, it was considered taboo to record phone calls. But eventually people became used to answering machines, and it soon became rude not to have

\footnotetext{
${ }^{9}$ http://www.gov.cn/zhengce/content/2017-07/20/content_5211996.htm

10 https ://www. cnbc. com/2017/04/27/kai-fu-lee-robots-will-replace-half-ofall-jobs.html

11 https://pandaily.com/kai-fu-lee-i-disagree-with-elon-musks-ai-willdestroy-humanity/

12 http://www. dailymail.co.uk/news/article-4918342/China-installs-20-millionAI-equipped-street-cameras.html
} 
an answering machine. Now it seems more polite to send a text message or email. Cultural attitudes toward technology are constantly evolving across space and time. What is considered okay or not okay at one point in time and space, may or may not be considered okay at another time or another place.

There are lots of ways to do good things with any new technology. Some of them work better in the court of public opinion, and some of them are more significant commercially. In the case of face recognition technology, there have been a few highly publicized cases where face recognition has helped reunite children with their parents. $^{13,14}$

Security applications impact more people. Many of us use face recognition to unlock our phones. Baidu uses face recognition to unlock the doors to the building. After I link my face to my badge, I do not need to bring my badge to get into the building; all I need is my face. Unlike American Express products, ${ }^{15}$ it is hard to leave home without my face.

\section{Electronic payments}

Payments are an even larger commercial opportunity. Cash is not used much in China these days, and credit cards never took off. Most people pay for things with bar codes on phones via mobile payment apps, such as WeChat and Alipay. Face recognition may soon replace bar codes.

When I check out of the Baidu cafeteria, I pay for my lunch by showing my face to the camera, and that is that. Face recognition is safer than a credit card. Anyone can steal a credit card (with or without a chip), but it is hard to steal my face.

The real problem with credit cards is friction, as pointed out by Kai-Fu Lee in the Davos speech mentioned above.

The number of daily mobile transactions on WeChat and Alipay exceeded 300 million. Such vigorous expansion of mobile payments will bring a huge change to consumption in China... Credit card companies earn 3 percent from merchants, return 2 percent to users and leave themselves with 1 percent. Credit cards are connected to the interests of these people, and it is hard to deter Americans from using credit cards. But America and Europe must find a more open model.

When I first visited China 25 years ago, everything was negotiable, and consequently, it took a long time to buy anything. In addition to the price, we also had to negotiate currency. There were many illegal currencies, as well as two legal currencies, one for locals (RMBs) and another for foreigners (FMBs). In theory, the two currencies were worth the same thing, but in practice, FMBs were worth more because they could be used in 'friendship stores' that sold goods that were not available elsewhere. But, FMBs were hard to use in rural areas where people had not

13 https://news.filehippo.com/2013/06/facial-recognition-app-to-find-missingchildren/

14 https://nakedsecurity. sophos.com/2017/06/02/facial-recognition-reunitesmissing-boy-with-his-dad-after-four-years/

15 http://www. thedrum.com/news/2016/07/03/marketing-moments-11-americanexpress-dont-leave-home-without-it 
seen them. FMBs were also hard to use because they came in large denominations. One time we owed a taxi driver a small fee, and all we had was a large note in FMBs. The driver did not have enough change, but he wanted our FMBs so much that he negotiated with a line of taxi drivers to borrow enough RMBs to make change. Needless to say, it took a long time to pay for that taxi ride.

There was another time when I wanted an alarm clock. My host was horrified when I accepted the initial bid of \$3. The vendor was also disappointed, so he threw in a free battery. I probably should have negotiated harder because that is how the game is played, but I needed the clock, and did not have much time.

When my son was in middle school, he attracted a large crowd by negotiating (remarkably effectively) with an experienced vendor. Both he and the crowd enjoyed the game, but at the end of the day, the vendor spent more time on the transaction than it was worth, and my son ended up with a souvenir that he never wanted.

Every time I go to China, it is a different country. These days, there is less negotiating, and almost no cash. I actually used cash recently to buy a cup of coffee. It can still be done (barely), but the vendor made it clear that that's not the way the game is played these days.

Even more recently, Baidu sent a bunch of us on a team building trip where we played lots of games. Some of games included negotiations of various kinds, including an old fashioned 'black market.'

Negotiating can be fun, even if it does not make much sense economically. From a practical point of view, it is important to come up with simple (fast) methods to pay for things with as little friction as possible. Kai-Fu Lee is correct when he points out that China now plays the payment game better than we do.

\section{Concluding remarks}

I was talking with someone from Germany the other day. When I mentioned that 'Made in Japan' used to be associated with poor quality, he mentioned that the same used to be true for 'Made in Germany.' It took a few decades for the economies in Japan and Germany to recover from World War II. So too, as the economy improves in China, we will quickly forget that 'Made in China' used to be associated with poor quality.

The future is with the next generation. The top universities in China have always been very good, but they are better today than they were 25 years ago, and they are on a trajectory to become the biggest and the best in the world.

China is investing big time (and long term) in what we do, both in the private sector as well as the public sector. Kai-Fu is bullish on his investments in AI and China, as well as Chinese talent. The Chinese government has announced a bold plan for AI with specific milestones for parity with the West in 2020, major breakthroughs by 2025 and the envy of the world by 2030 . 